\title{
Modelos de Estado desenvolvimentista
}

\author{
Models of Developmental State
}

\author{
Luiz Carlos Bresser-Pereira*
}

\begin{abstract}
Resumo: Este artigo define do Estado desenvolvimentista de maneira ampla, entende-o como alternativa histórica ao Estado liberal, e distingue cinco modelos de Estado desenvolvimentista. Quatro deles caracterizaram os Estados centrais originais, como a Inglaterra, centrais retardatários, como a Alemanha, periféricos independentes, como a Coreia do Sul, e periféricos nacional-dependentes, como o Brasil. O quinto modelo é o de um segundo desenvolvimentismo que ocorre nos países centrais, após a Segunda Guerra Mundial, no quadro do corporativismo e da social-democracia, nos Anos Dourados do Capitalismo.
\end{abstract}

Palavras-chave: Estado desenvolvimentista; Liberalismo; Nacionalismo; Socialdemocracia; Corporativismo

\begin{abstract}
This paper defines the developmental state as a historical alternative to the liberal state, and distinguishes five models of developmental state. Four of them characterized the original central states such as England, laggard centrals like Germany, independent peripherals like South Korea, and national dependents peripherals like Brazil. The fifth model is a second type of developmentalism that takes place in the central countries after World War II in the framework of corporatism and social democracy in the Golden Years of Capitalism.
\end{abstract}

Keywords: Developmental State; Liberalism; Nationalism; Social Democracy; Corporatism

JEL Code: O10; O11; O19

\footnotetext{
* Professor emérito da Fundação Getúlio Vargas (FGV-SP). E-mail: bresserpereira@gmail.com. Agradeço a Eleutério Prado pelos comentários. Versão traduzida, revista e ampliada de trabalho publicado na Revista CEPAL, 128, p. 39-52, agosto 2019.
} 


\section{Introdução}

Na década de 1950, cientistas políticos e economistas brasileiros definiram "desenvolvimentismo" como um conjunto de ideias políticas e estratégias econômicas que promoveram a rápida industrialização do Brasil e apoiaram a coalizão de classes sociais para o desenvolvimento nacional. Hélio Jaguaribe (1962, p. 208) apontou no início dos anos 1960 que a tese central do desenvolvimentismo era que a promoção do desenvolvimento econômico e a consolidação da nacionalidade constituíam dois aspectos interrelacionados de um único processo emancipatório. Graças ao "nacional-desenvolvimentismo", a sociedade brasileira deixou para trás o Estado patrimonial que caracterizou a política do país até 1930. Outros países da América Latina, como México e Argentina, e países do leste da Ásia, como a Coreia do Sul, Cingapura e Taiwan, cresceram também graças à adoção de uma estratégia teoricamente baseada em uma combinação do desenvolvimentismo clássico com as concepções macroeconômicas keynesianas. Nesses países, a intervenção estatal foi combinada com um setor privado dinâmico. No início dos anos 1980, Chalmers Johnson (1982), na tentativa de entender o extraordinário desenvolvimento econômico do

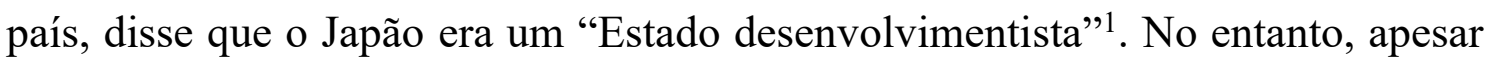
do extraordinário êxito desses países do Leste Asiático, a partir do momento em que o capitalismo se tornou neoliberal, na virada dos anos 1970 para os anos 1980, a palavra "desenvolvimentismo" se tornou depreciativa, sinônimo de irresponsabilidade fiscal ou populismo. Essa manobra retórica era uma maneira de reafirmar a nova hegemonia neoliberal e neoclássica, o Consenso de Washington. É verdade que desde o final da década de 1970, diante da crise resultante do segundo choque do petróleo, vários países latino-americanos se recusaram a fazer os ajustes macroeconômicos necessários e optaram pelo populismo fiscal e cambial, o primeiro justificado por uma teoria supostamente keynesiana. Isso abriu espaço para a grande crise da dívida externa dos anos 1980, a qual fragilizou os países da região e criou as condições para a hegemonia neoliberal na América Latina. Na década de 1990, as políticas e reformas neoliberais não cumpriram suas

\footnotetext{
${ }^{1}$ O termo Estado geralmente é escrito em letras maiúsculas, o que parece razoável, considerando que designa a principal instituição de uma empresa. No entanto, quando se fala em Estado desenvolvimentista ou patrimonial, e a propósito do estado-nação, é feita referência a um sistema político ou forma de governo no primeiro caso e a uma forma de sociedade político-territorial soberana no segundo, portanto, nesses casos, as letras minúsculas serão usadas.
} 
promessas. Os países submetidos à ordem neoliberal incorreram em déficits em conta corrente que foram entendidos como "poupança externa" quando não passavam de populismo cambial ${ }^{2}$, e resultaram em baixa taxa de crescimento, maior instabilidade financeira e um forte aumento da desigualdade.

Entretanto, no início dos anos 2000, diante da incapacidade das reformas neoliberais de fazer os países da região retomarem o crescimento, o desenvolvimentismo emergiu mais uma vez, tanto como fenômeno histórico (como estratégia e forma de coordenar o capitalismo alternativa ao liberalismo econômico), quanto como uma nova teoria de desenvolvimento econômico. Enquanto fenômeno histórico, ele foi associado a governos de esquerda que, ao buscar se identificar com um "desenvolvimentismo social”, muitas vezes levou à irresponsabilidade ou populismo fiscal. Enquanto programa de pesquisa, teoria e estratégia nacional de desenvolvimento, economistas, cientistas políticos e sociólogos, incluindo o autor deste artigo, propuseram uma nova abordagem teórica inovadora que recebeu o nome de Novo Desenvolvimentismo, e logo mostrou ser uma alternativa ao Desenvolvimentismo Clássico ou Estruturalismo Latino-Americano ${ }^{3}$.

O Novo Desenvolvimentismo está voltado para os países de renda média e representa uma tentativa de renovar a teoria econômica. Sua macroeconomia do desenvolvimento baseia-se na tendência à sobrevalorização cíclica e crônica da taxa de câmbio - uma tendência que a torna apreciada no longo prazo e, assim, desconecta as empresas industriais da demanda tanto interna quanto externa. Ela se concentra nos cinco preços macroeconômicos (a taxa de lucro, a taxa de juros, a taxa de câmbio, a taxa salarial e a taxa de inflação) que o mercado não tem capacidade de definir corretamente. Por seu lado, a economia política do Novo Desenvolvimentismo, da qual este artigo sobre os modelos de Estado desenvolvimentista faz parte, está baseada nos conceitos de Estado desenvolvimentista, capitalismo desenvolvimentista e coalizões de classe.

Tomando como referência os primeiros países a se industrializarem (Inglaterra, Bélgica e França), o caminho histórico que eles seguiram pode ser

\footnotetext{
${ }^{2}$ O conceito de populismo cambial tem sua origem nos trabalhos de Adolfo Canitrot (1975) e Carlos DíazAlejandro (1981). É um conceito fundamental para o Novo Desenvolvimentismo, cujos princípios macroeconômicos se concentram nos déficits ou superávits da taxa de câmbio e da conta corrente.

${ }^{3}$ Ver Bresser-Pereira $(2016,2019)$ e Bresser-Pereira, Oreiro e Marconi (2016).
} 
resumido em alguns fatos estilizados. No final da Idade Média, as monarquias absolutas se aliaram à burguesia nascente para derrotar os senhores feudais e formar o Estado absoluto e mercantilista. A revolução industrial ocorreu no quadro da primeira forma de desenvolvimentismo: o mercantilismo. Entre 1846, quando o Reino Unido abriu afinal a sua economia, até o crash de 1929, o Estado foi liberal. A Grande Depressão deu origem ao New Deal e, depois da Segunda Guerra Mundial, à Era Dourada do Capitalismo. Para os países ricos da Europa, este foi o segundo desenvolvimentismo, caracterizado por uma intervenção moderada do Estado na economia, uma política macroeconômica ativa, estabilidade financeira, crescimento rápido, uma redução moderada da desigualdade e uma coalizão de classes desenvolvimentista: o fordismo. ${ }^{4}$ Essa nova fase duraria cerca de 30 anos, após os quais o capitalismo central, então dominado por uma coalizão de classes financeiro-rentista, restabeleceu o liberalismo econômico, agora radical (o neoliberalismo), que foi dominante por outros 30 anos, entrando em profunda crise a partir da crise financeira global de 2008. Este artigo não cobrirá cada fase deste processo a longo prazo. Em vez disso, seu objetivo é examinar o Estado desenvolvimentista no quadro do desenvolvimento capitalista; é definir as quatro formas históricas de revolução industrial e capitalista, os quatro respectivos modelos de Estado desenvolvimentista, e um quinto modelo - aquele que surgiu no pós-Guerra, o qual, para os países ricos, foi um segundo desenvolvimentismo.

As duas instituições de coordenação econômica e social do capitalismo são o Estado e o mercado. Enquanto o mercado carece de vontade (embora os interesses daqueles que nele operam estejam presentes), o Estado representa a lei e, portanto, a vontade política. É através do Estado que a ação coletiva é exercida e as nações regulam a vida social em busca dos objetivos políticos que as sociedades modernas estabeleceram: autonomia nacional, democracia, segurança, liberdade, bem-estar, justiça social e proteção ambiental. É através do mercado que as empresas competem, que os preços são formados e que os recursos são alocados com eficiência entre os vários setores da economia. É através do mercado que os setores competitivos da economia são coordenados. É através do Estado que o

\footnotetext{
4 "Fordismo" é o nome dado pela Escola Francesa de Regulação ao "modo de regulação" do capitalismo liderado pelos Estados Unidos desde a Nova Aliança até a década de 1970. Era uma coalizão de classes para o desenvolvimento, caracterizada por consumo de massa, grandes empresas monopolistas e burocráticas e algum grau de redução da desigualdade, no sentido de que os salários aumentaram junto com a produtividade e que o progresso técnico permitiu economizar capital.
} 
mercado é regulado, os setores econômicos não-competitivos são coordenados, e uma política macroeconômica ativa pode garantir o equilíbrio macroeconômico e criar condições necessárias para o investimento e a inovação, o pleno emprego e o desenvolvimento econômico sustentável.

\section{Que Estado desenvolvimentista?}

A presença do Estado desenvolvimentista ao longo da história do desenvolvimento capitalista não é um produto do acaso. A lógica do estado-nação é a do desenvolvimento econômico e da concorrência. Como foi observado por Ernest Gellner (1996), o estado-nação contrasta com o império clássico ou préindustrial. O império é a unidade político-territorial que caracterizou as sociedades mais avançadas da antiguidade, enquanto o estado-nação é a sociedade políticoterritorial própria do capitalismo. A lógica do estado-nação é a do crescimento econômico que o Estado (o sistema constitucional-legal e a organização que garante) deve, portanto, promover. Ao regular as economias capitalistas, o Estado moderno assume duas formas básicas, a desenvolvimentista e a liberal, que também são as duas formas de organização econômica e política do capitalismo já que o Estado, como instituição fundamental das sociedades modernas, define a natureza do capitalismo. O Estado liberal limita-se a garantir a propriedade e os contratos, e a manter saudáveis as finanças públicas, deixando a coordenação de todas as outras atividades nas mãos do mercado.

Chalmers Johnson $(1982,1999)$ definiu o Estado desenvolvimentista como um Estado que coloca o desenvolvimento econômico como um objetivo prioritário; intervém na economia não apenas através da regulamentação, mas também diretamente; possui uma burocracia pública pequena mas altamente qualificada, à qual são atribuídos poderes efetivos, enquanto os poderes Legislativo e Judiciário permanecem em segundo plano; protege a indústria manufatureira nacional com políticas industriais; facilita a importação de máquinas; separa a tecnologia estrangeira, na qual possui um interesse acentuado, do capital estrangeiro, no qual não tem interesse; cria instituições financeiras estatais; adota incentivos fiscais e de crédito, mas sempre de forma temporária, sujeitos a avaliações constantes; fornece sólido apoio governamental para ciência e tecnologia; evita aprovar leis muito detalhadas, permitindo que as empresas tomem a iniciativa de acordo com a orientação discricionária da burocracia 
pública; ${ }^{5}$ adota um orçamento consolidado de investimento público; e controla suas contas comerciais e financeiras externas e, portanto, a taxa de câmbio. Peter Evans (1992) apontou duas características do Estado desenvolvimentista do século XX, a saber, a capacidade de sua burocracia pública e sua firme inserção na sociedade e na comunidade empresarial. Johnson e Evans consideram que a burocracia pública desempenha um papel estratégico no Estado desenvolvimentista, o que é razoável, mas também os empresários industriais desempenham um papel decisivo.

Estas são excelentes definições do Estado desenvolvimentista, mas prefiro defini-lo de maneira mais ampla. Um Estado é desenvolvimentista quando: (a) considera o crescimento econômico como seu principal objetivo; (b) intervém de forma moderada no mercado, planejando o setor não competitivo da economia e adotando políticas industriais estratégicas; (c) adota uma política macroeconômica ativa, limitando os déficits orçamentários e em conta corrente e assegurando que os cinco preços macroeconômicos atinjam o nível "certo", em particular a taxa de câmbio; e (d) possui o apoio político de uma coalizão de classes para o desenvolvimento, formada por empresários, trabalhadores, funcionários da burocracia pública e setores da antiga classe dominante que exercem poder político e apoiam uma estratégia nacional de desenvolvimento, coalizão que, assim, se opõe a uma coalizão liberal-conservadora composta por capitalistas rentistas, financistas e os interesses estrangeiros. ${ }^{6}$

Segundo Peter Evans (1992, p. 12), há uma terceira alternativa para o Estado: além da liberal e da desenvolvimentista: o Estado é "predatório", quando não é capaz de impedir que os políticos persigam seus próprios objetivos. Nele, os vínculos pessoais constituem a única fonte de coesão, e a maximização dos resultados individuais está acima da busca de objetivos coletivos, ou seja, virtudes republicanas estão excluídas. Existem Estados predadores em países préindustriais que ainda não passaram por uma revolução industrial e capitalista. Seus governantes afirmam serem desenvolvimentistas ou então liberais, mas isso significa pouco ou nada.

\footnotetext{
${ }^{5}$ Esta é a ideia básica da reforma gerencial do Estado que eu promovi no Brasil.

6 As coalizões conservadoras nos países em desenvolvimento estão associadas às elites liberais internacionais e, portanto, são "liberais" no sentido de defender, embora não necessariamente praticar, o liberalismo econômico.
} 
O Estado é uma instituição humana falível, mas a tese liberal que o Estado é sempre incapaz não corresponde à realidade. A história mostra que o Estado desempenhou um papel fundamental em todos os episódios de industrialização; todos os casos de decolagem ou revolução industrial ocorreram no quadro de um Estado desenvolvimentista, começando com a revolução industrial britânica, que ocorreu em um contexto de mercantilismo, a primeira forma histórica de desenvolvimentismo. Isto é devido a motivos sólidos. O mercado é uma excelente instituição para coordenar atividades econômicas competitivas, mas é incapaz de fazê-lo no caso de atividades não competitivas. Além disso, não consegue coordenar bem os preços macroeconômicos. Para que uma sociedade deixe de ser agrária e se torne industrial, deve haver um projeto desenvolvimentista nacional.

Um aspecto importante é se as elites agrícolas fazem parte das coalizões de classes desenvolvimentistas. ${ }^{7}$ Como Marcus Ianoni (2014, p. 99) apontou, na Coreia do Sul e na província chinesa de Taiwan, a sociedade rural convergiu com o desenvolvimento industrial ao invés de se opor a ele. O mesmo pode ser dito das elites agrárias alemãs que Bismarck incorporou com sucesso a seu arranjo político. No Brasil, argumenta-se frequentemente que as elites agrárias se opuseram ao Estado desenvolvimentista, tanto no período pré-industrial quanto hoje. No entanto, no que diz respeito à agricultura, há uma distinção crucial entre países como o Brasil, por um lado, e a maioria dos países da Europa e da Ásia Oriental, por outro. Nestes, a agricultura é voltada para o mercado interno, enquanto no Brasil inicialmente o café e a cana-de-açúcar e agora também a soja e o suco de laranja, são produtos básicos de exportação. E são causas da chamada "doença holandesa", que consiste em uma apreciação de longo prazo da moeda local em países que exportam commodities, porque elas podem ser exportadas com lucro a uma taxa de câmbio substancialmente mais apreciada do que aquela que é necessária para que sejam competitivas as empresas industriais que utilizam a melhor tecnologia existente no mundo. É. portanto, uma desvantagem competitiva que, se não for neutralizada, impede a industrialização. A doença holandesa foi neutralizada no Brasil durante sua fase de revolução nacional e industrial (19301980) graças a um imposto disfarçado sobre as exportações que os cafeicultores denominaram "confisco cambial”, que, na prática, se expressava através de

\footnotetext{
${ }^{7}$ Veja Bresser-Pereira e Ianoni (2017) para uma revisão abrangente das formas históricas das coalizões de classes para o desenvolvimento.
} 
sistemas múltiplos de câmbio ou então tarifas de importação e subsídios à exportação de manufaturados. Foi esse "imposto" que os levou a se oporem à industrialização. ${ }^{8}$ No entanto, nas décadas de 1930 a 1950, a participação da oligarquia agrícola não-exportadora localizada no Sul e no Nordeste do país foi fundamental para o sucesso do pacto nacional-desenvolvimentista de Getúlio Vargas.

A definição de Estado desenvolvimentista proposta aqui não é prescritiva, mas uma generalização do comportamento dos países em desenvolvimento, particularmente os do Leste Asiático e do Brasil na época em que foram industrializados. Supondo-se que a conduta dos Estados desenvolvimentistas não tenha sido muito diferente, consideremos o caso da Coreia do Sul e as políticas econômicas que permitiram que ela realizasse o catching up: altas tarifas de importação, de 30\% a 40\% nos anos 1970, e de 20\% a 30\% nos anos 1980; grande número de barreiras não tarifárias; grandes subsídios à exportação; pequenos déficits fiscais; uma baixa relação dívida/PIB; um mercado financeiro muito regulado; taxas de juros muito baixas, geralmente negativas; controle estrito da taxa de câmbio; controle rigoroso das entradas e saídas de capital; e uma taxa média de inflação de $17,4 \%$ na década de 1960 e de $19,8 \%$ na década de $1970 .^{9}$

\section{Modelos de Estado desenvolvimentista}

Quando essa definição ampla de Estado desenvolvimentista é adotada, surge uma característica fundamental da história do desenvolvimento capitalista: todas as revoluções industriais (o momento decisivo da revolução capitalista em cada país) foram realizadas sob a liderança de um Estado desenvolvimentista. Inglaterra, Bélgica e França foram industrializadas na época do mercantilismo, que foi a primeira forma de desenvolvimentismo; a Alemanha, sob a égide de Bismarck, e os Estados Unidos, com Alexander Hamilton; no Japão, a

\footnotetext{
${ }^{8}$ A neutralização da doença holandesa no Brasil nos anos 1950 foi realizada através de sistemas múltiplos de câmbio, e, depois, entre 1960 e 1990, através de altas tarifas de importação e subsídios a exportação de manufaturados. Graças a isto e a taxas de juros baixas, o Brasil cresceu de forma extraordinária e se transformou em um grande exportador de bens manufaturados. A partir de 1990, porém, no quadro do Consenso de Washington, as tarifas sobre importação de manufaturados foram baixadas e os subsídios à sua exportação, eliminados, enquanto a taxa de juros aumentou para atrair capitais externos, e, em consequência, o país entrou em grave processo de desindustrialização e quase-estagnação.

${ }^{9}$ Este resumo é baseado no trabalho de Ha-Joon Chang (2002b) e em uma aula correspondente ao sexto programa latino-americano avançado sobre o exame de macroeconomia e economia desenvolvimentistas (Laporde), ministrado em São Paulo em 11 de janeiro de 2016.
} 
industrialização ocorreu sob o rígido controle do Estado Meiji; no Brasil e no México, a industrialização ocorreu no âmbito do nacional-desenvolvimentismo.

Para corroborar o exposto, é conveniente fazer uma classificação dos modelos de Estado desenvolvimentista e os respectivos países. Primeiro, considerarei apenas o modelo de Estado no momento em que realizaram sua revolução industrial, e distinguirei o modelo central do Estado desenvolvimentista do modelo periférico, subdividindo estas duas categorias; no primeiro caso, conforme o momento em que realizaram sua revolução industrial, e, no segundo caso, de acordo com o grau de autonomia nacional:

O modelo de Estado desenvolvimentista é central se, no final do século XVIII, contava com uma sociedade agrária sofisticada; é central original, se esteve entre os primeiros estados-nação a realizar sua revolução industrial entre o final do século XVIII e o início do século XIX, como foi o caso da Inglaterra, Bélgica e França; é central tardio, se sua industrialização ocorreu na segunda metade do século XIX, como foi o caso da Alemanha, da Itália e dos Estados Unidos.

O modelo de Estado desenvolvimentista é periférico se, para realizar sua revolução industrial, teve, primeiro, que se libertar do imperialismo industrial dos estados-nação de desenvolvimento original; é periférico independente se suas elites foram nacionalistas do ponto de vista econômico, como foi o caso da Coreia do Sul, da Malásia, da China, da Índia, e do Vietnã; é periférico nacionaldependente se suas elites foram ambíguas ou contraditórias em suas relações com as elites dos países centrais, ora agindo com independência e definindo com as classes populares uma estratégia nacional de desenvolvimento, ora se submetendo à hegemonia ideológica dos países ricos, como é o caso da Argentina, do Brasil, e do México. Esses países, que foram nacionalistas para realizar sua revolução capitalista, a partir de meados dos anos 1980 se submeteram ao Consenso de Washington e passaram a ficar muito para trás dos países periférico-independentes.

Temos uma quinta categoria de Estado desenvolvimentista: o caso dos países que foram originalmente desenvolvimentistas, tornaram-se liberais, mas voltaram a ser desenvolvimentistas, a experimentar um segundo desenvolvimentismo. Foi o que ocorreu nos países centrais no pós-Guerra, na Era de Ouro do capitalismo. 
Existem ainda os países pré-industriais que atualmente estão tentando efetuar a revolução, além de outros simplesmente pobres, mas nenhuma dessas duas categorias será abordada neste artigo.

\subsection{O modelo central original}

Com os quatro primeiros modelos de Estado desenvolvimentista, os países em questão alcançaram um grau razoável de autonomia e adotaram uma estratégia de crescimento na qual o Estado e o mercado desempenhavam papéis importantes. O modelo central original foi estudado por grandes economistas, de Adam Smith e Karl Marx a historiadores econômicos como Fernand Braudel, Paul Bairoch e David Landes. Ele se desenvolveu no contexto de um Estado desenvolvimentista mercantilista, e não de um Estado liberal. Portanto, a crítica liberal ao mercantilismo enquanto fase histórica do capitalismo é gravemente equivocada. $\mathrm{O}$ Estado mercantilista, ou absoluto, foi o tempo das primeiras revoluções industriais e capitalistas que mudaram de forma radical a história do mundo. O modelo central original de Estado desenvolvimentista envolveu uma coalizão de classes formada pelo monarca, sua nobreza patrimonial (cuja renda provinha do tesouro do Estado e não da terra) e a numerosa e rica burguesia mercantil que estava surgindo. Sua estratégia desenvolvimentista foi expandir o mercado interno, ampliando tanto quanto possível as fronteiras do estado-nação através de guerras contra os povos vizinhos visando anexá-los. Embora estivesse criando uma economia de mercado, o Estado mercantilista não hesitava em intervir na economia e organizar monopólios no quadro da aliança entre o monarca absoluto e a grande burguesia que pagava impostos para financiar as guerras, e, em troca, passava a contar com um mercado interno cada vez mais amplo e seguro.

A crítica radical que Adam Smith fez da teoria mercantilista é compreensível. Ele não estava fundando a teoria econômica (seus fundadores foram os economistas mercantilistas), mas estava fundando uma nova escola de economia - uma escola liberal - a Escola Clássica da qual participaram economistas brilhantes como Malthus, Ricardo e Marx. Mas os economistas mercantilistas, embora dessem importância demasiada aos saldos em contacorrente dos países, foram também economistas notáveis, como Schumpeter em sua monumental History of Economic Analysis (1954). 


\subsection{O modelo central tardio}

O modelo central tardio caracterizou países como Alemanha, Itália, Suécia e Estados Unidos. O estudo clássico desse modelo desenvolvimentista foi feito por Alexander Gerschenkron (1962), que analisou os países europeus que se desenvolveram na segunda metade do século XIX e encontrou neles um maior grau de intervenção do Estado. Esses países tiveram que enfrentar o imperialismo industrial da Inglaterra e da França, países que, como Friedrich List (1999) disse em 1846, tentaram "chutar a escada" da Alemanha com o argumento que a Alemanha tinha vantagens comparativas na agricultura. ${ }^{10}$ Neste país, o Estado desenvolvimentista foi chamado bismarckiano, porque sua revolução industrial foi liderada por Otto von Bismarck (1815-1898), que combinou intervenção estatal e financiamento pelos novos bancos de investimento, e serviu de exemplo para outros países centrais de industrialização tardia. Em seus escritos de 1962 sobre o desenvolvimentismo bismarckiano, Hélio Jaguaribe observava que nesse modelo o mercado interno era reservado à indústria nacional e o Estado desempenhava o papel de árbitro entre partes conflitantes.

Embora o mercado interno dos Estados Unidos também tenha sido reservado para fabricantes nacionais, o papel do Estado na industrialização do país era sistematicamente disfarçado porque a ideologia liberal era predominante. Seu primeiro secretário do Tesouro, Alexander Hamilton (1791), não foi apenas um dos três grandes filósofos políticos dos Federalist Papers, mas também um economista desenvolvimentista - mais precisamente, o primeiro dos economistas desenvolvimentistas. Seu trabalho clássico Report on Manufactures (1791), sobre a necessidade de proteger a indústria nascente americana, inspirou uma política de promoção industrial duradoura e coerente que foi mantida até 1939, quando os Estados Unidos finalmente reduziram suas tarifas alfandegárias, que até então eram muito altas. Segundo Paul Bairoch (1993, p. 40-51), a tarifa média de importação no século XIX e até a década de 1930 variou de 35\% a 48\%, tornando o país, segundo esse renomado historiador da economia, em um bastião do protecionismo. Ha-Joon Chang (2002a, p. 24-32) apresenta dados adicionais

\footnotetext{
10 A frase "chutar a escada" foi usada inicialmente por Friedrich List em 1846 para descrever o comportamento da Inglaterra, que, usando os argumentos da economia liberal clássica, procurou convencer os alemães a não se industrializarem (ver List, 1999). Esse argumento descreve a atitude atual dos países ricos em relação aos países em desenvolvimento. Ha-Joon Chang (2002a) apropriou-se da frase e aplicoua com grande sucesso e relevância.
} 
demonstrando o exposto acima. $\mathrm{O}$ fato de as tarifas serem muito mais altas que as do Reino Unido e da França, onde haviam sido reduzidas muito antes, constitui uma estratégia desenvolvimentista, mas que não pode ser explicada com o argumento da indústria infante. A meu ver, as tarifas sobre a importação de bens manufaturados se mantiveram elevadas muito depois de a indústria americana ter deixado de ser nascente, porque, dessa forma, os policymakers americanos neutralizavam intuitivamente a doença holandesa ${ }^{11}$. Os extraordinários recursos naturais dos Estados Unidos, incluindo o petróleo, resultaram em uma sobrevalorização da taxa de câmbio a longo prazo, porque essas mercadorias poderiam ser exportadas e gerar lucros a uma taxa de câmbio mais alta do que aquela aplicável aos produtos manufaturados. Portanto, essas tarifas não constituíram tanto um sistema "protecionista", entendida esta palavra em termos depreciativos, mas um meio de neutralizar a doença holandesa em relação ao mercado interno.

\subsection{O modelo periférico independente}

O terceiro modelo de Estado desenvolvimentista, o modelo periférico independente, tem o Japão como padrão. Os japoneses se sentiram humilhados quando foram forçados a abrir o comércio com o Ocidente em 1854, sob a ameaça dos canhões do Comodoro Perry ${ }^{12}$. Após a restauração de Meiji em 1868 - a revolução nacionalista japonesa que libertou o país da tutela do Ocidente -, o país adotou a estratégia de copiar as tecnologias e instituições ocidentais. Nos 40 anos seguintes, houve uma rápida industrialização sob o controle direto do Estado japonês. Foi nesse período que a tecnologia foi copiada. No final dele, entre 1908 e 1910, houve a cópia das instituições com a decisão de se privatizarem empresas

\footnotetext{
${ }^{11}$ A maneira correta de neutralizar a doença holandesa (ou seja, a sobrevalorização a longo prazo da taxa de câmbio, porque as mercadorias podem ser exportadas com sucesso a uma taxa de câmbio consideravelmente mais alta do que dos produtos industriais comercializáveis) é impor uma retenção variável nos preços das mercadorias que causam essa situação. As altas tarifas de importação apenas neutralizam a doença holandesa no lado do mercado interno, pois aumentam o preço das importações, enquanto vários regimes cambiais podem neutralizá-la tanto do lado da importação quanto da exportação. 12 "Oeste" significa o grupo de países ricos na região do Attântico Norte, além da Austrália, Nova Zelândia, Japão e os três países do sul da Ásia que no século XX estavam no mesmo nível: República da Coréia, Província chinesa de Taiwan e Cingapura. Portanto, o Ocidente não é um conceito geográfico. Seus membros fazem parte do império moderno, sob a liderança dos Estados Unidos. São países que têm em comum altos níveis de conhecimento e salários, que buscam proteger os lucros de suas empresas. Eles são organizados militarmente no âmbito da OTAN e seus principais instrumentos econômicos são o Fundo Monetário Internacional e o Banco Mundial.
} 
em setores competitivos ${ }^{13}$. Os antigos samurais que na era Tokugawa (1603-1868) constituíam uma pequena aristocracia guerreira, participaram como soldados na restauração de Meiji. Nos primeiros anos da restauração formaram uma classe média de burocratas e, mais tarde, com a privatização, tornaram-se empresários. A privatização não teve uma marca ideológica: os japoneses simplesmente copiaram o modelo institucional ocidental no qual o mercado se mostrou uma instituição bem-sucedida em coordenar atividades econômicas competitivas.

Entre os estudos clássicos do desenvolvimentismo periférico independente estão os de Barbosa Lima Sobrinho (1973) e Chalmers Johnson (1982), sobre o Japão, de Alice Amsden (1989) sobre a Coreia do Sul, e de Robert Wade (1990) sobre Taiwan. Esses livros mostram claramente o impacto positivo da política industrial na industrialização desses países. No entanto, com exceção parcial do trabalho de Robert Wade, eles não apresentam uma análise da política macroeconômica ativa adotada, a qual foi essencial para explicar o catching up desses países. Neste plano, os países do Leste da Ásia buscaram, em primeiro lugar, limitar os empréstimos solicitados no exterior, bem como a penetração do mercado interno pelas empresas multinacionais; em segundo lugar, procuraram manter corretos os cinco preços macroeconômicos: a taxa de lucro, a taxa de juros, a taxa de salários, a taxa de inflação e, acima de tudo, a taxa de câmbio. Para manter as taxas de câmbio competitivas os formuladores de políticas dos países asiáticos acima mencionados desfrutaram de uma vantagem significativa em relação aos seus pares latino-americanos: seus países não exportam commodities e, portanto, não tiveram que neutralizar a doença holandesa.

A partir do exemplo do Japão, os demais países do Leste da Ásia seguiram o mesmo caminho de acordo com a metáfora dos "gansos voadores" proposta originalmente e com forte poder de previsão por Kaname Akamatsu (1962): a maneira como os países asiáticos copiavam o modelo japonês em revoadas. Os primeiros a copiar o Japão foram a Coreia do Sul, Taiwan e Cingapura; depois Malásia e Indonésia; e finalmente China e Vietnã ${ }^{14}$. A China, que desde meados

\footnotetext{
${ }^{13}$ A partir dos dados de Angus Maddison, infere-se que a revolução industrial japonesa ocorreu nos anos da Segunda Guerra Mundial, mas a capacidade desses dados para detectar revoluções industriais é limitada. O Japão só teve forças para iniciar guerra contra a Rússia em 1905 e contra a China em 1936 porque já havia desenvolvido uma poderosa indústria manufatureira antes da Segunda Guerra Mundial.

${ }^{14}$ No caso da República da Coreia, o modelo japonês foi imposto por mais de 30 anos de domínio colonial japonês e permaneceu após a independência do país. Como aponta Atul Kohli (1999, p. 94), em 1940 a República da Coréia já era um país com um grau relativamente alto de industrialização.
} 
do século XIX sofreu uma grande decadência sob o imperialismo industrial do Ocidente, realizou sua revolução nacional e supostamente socialista em 1949. A revolução nacional foi completada pela revolução industrial, que foi dividida em duas partes, a primeira de 1949 a 1978 sob a liderança de Mao Zedong (18931976) e a segunda de 1988 a 2010 com Deng Xiaoping (1904-1997). Mao achava que estava cumprindo a primeira fase da revolução socialista chinesa, quando na verdade estava realizando a primeira fase da revolução capitalista: sob seu comando, a China foi um estado-nação genuinamente independente, educou sua população e desenvolveu sua infraestrutura e indústria básica - atividades que o Estado geralmente pode realizar de maneira eficaz e com razoável eficiência se contar com burocratas competentes. A segunda fase, ainda não terminada, caracterizada por um crescimento extraordinário e de longa duração, levou à introdução do capitalismo, à privatização e à diversificação da produção. Como no Japão, o setor competitivo da economia foi privatizado e deixado por conta das forças do mercado, enquanto o Estado manteve o controle político, planejou o setor não competitivo e implementou uma política macroeconômica ativa para garantir que os cinco preços se mantivessem certos, em particular a taxa de câmbio.

\subsection{O modelo periférico nacional-dependente}

O quarto modelo de Estado desenvolvimentista é o modelo periférico nacional-dependente. Uso um oximoro para denominá-lo para acentuar o caráter ambíguo e contraditório das elites latino-americanas. Os empresários industriais que dele participam ora são nacionalistas e desenvolvimentistas, ora são liberais e dependentes porque, ao contrário dos empresários asiáticos, facilmente se sentem "europeus" e têm dificuldade em se identificar com o povo mestiço de seu país, ou então porque têm medo de uma radicalização política da esquerda, como aconteceu na América Latina depois da Revolução Cubana de 1959. Não surpreendentemente, os países associados ao modelo periférico nacionaldependente não tiveram tanto sucesso como os que adotaram o modelo periférico independente. Os países do modelo periférico nacional-dependente se industrializaram no pós-Guerra, completando assim sua revolução capitalista, mas não conseguiram manter boas taxas de crescimento desde 1980.

Os principais analistas do Estado desenvolvimentista na América Latina foram Raúl Prebisch, Celso Furtado, Aníbal Pinto e Ignácio Rangel. Somados a 
Rosenstein-Rodan, Arthur Lewis, e Albert Hirschman, eles fizeram parte do Desenvolvimentismo Clássico, cujas contribuições fundamentais foram feitas nas décadas de 1950 e 1960. Para essa escola de pensamento em conflito com a Escola Neoclássica, a industrialização era uma condição necessária para o desenvolvimento que o livre jogo das forças do mercado não lograva assegurar. Seus economistas, portanto, defenderam o planejamento econômico ou uma política industrial. Até o final dos anos 1970 esta estratégia foi bem-sucedida. Em 1980, porém, os países em desenvolvimento que haviam tentado crescer com poupança externa entraram em grave crise financeira e se enfraqueceram, enquanto, no Norte, em torno desse ano, ocorreu a "virada neoliberal": os países ricos abandonaram sua estratégia social-democrática e desenvolvimentista e transformaram o Banco Mundial, que era uma agência internacional comprometida com o desenvolvimentismo, em um instrumento do Consenso de Washington.

Desde então as taxas de crescimento caíram tanto no centro quanto na periferia do capitalismo. O Brasil, onde o crescimento da renda per capita aumentou quase 4\% ao ano durante a revolução industrial (1930-1980), desde 1981 cresce a uma taxa média per capita de $0,8 \%$ ao ano. No México e nos demais países em desenvolvimento, exceto os países do Leste e do Sudeste da Ásia que adotaram o modelo periférico independente, aconteceu a mesma coisa - a quaseestagnação.

Na década de 2000, uma explicação para o fato dominou literatura especializada em desenvolvimento econômico, o conceito de "armadilha da renda média" foi formulado para explicar a menor taxa de crescimento em um grupo dos chamados países de renda média ${ }^{15}$. Na literatura especializada, chegou-se a uma conclusão óbvia: países com altas taxas de crescimento (por exemplo, mais de 4\% ao ano) por um período relativamente longo (como cinco anos) mais tarde experimentam um declínio relativamente grande nessa taxa (abaixo de 2,5\% ao ano, por exemplo). Após identificar esses períodos, comuns a grupos totalmente diferentes de países, a literatura especializada tentou usar estudos econométricos para determinar a causa da desaceleração, mas não encontrou respostas satisfatórias. Suas conclusões nada mais são do que tautologias, como "falta de diversificação industrial," ou "taxa de crescimento alta demais" ou argumentos

\footnotetext{
${ }^{15}$ Eichengreen, Park e Shin (2014), Jankowska, Nagengast e Perea (2012), e Kharas e Kohli (2011).
} 
genéricos demais, como "investimento insuficiente em educação". Na verdade, conforme argumentei em Bresser-Pereira (2019), não foi o fato de haverem alcançado um nível de renda médio, mas foi um fato histórico novo: a adoção da abertura comercial e da abertura financeira a partir do final dos anos 1980, que levou os países latino-americanos a deixar de neutralizar a doença holandesa e a praticar juros muito mais altos e, em consequência, parar de crescer. Além disso, e diferentemente dos países do Leste da Ásia, esses países praticaram políticas fiscais irresponsáveis que transformaram poupanças públicas geralmente positivas nos anos 1970 em despoupança pública a partir dos anos 1980, inviabilizando, assim, o necessário financiamento do desenvolvimento econômico.

A explicação de Ben R. Schneider (1999) - que o Leste Asiático contou com uma burocracia menos formal e com mais poder - é parte da explicação. Certamente, uma burocracia profissional com maiores poderes no campo econômico deve ser preferida, mas deve-se notar que as burocracias públicas do México e especialmente do Brasil eram fortes o suficiente para alcançar a industrialização antes de 1980, e não há razão para pensar que elas foram enfraquecidas a partir dos dessa década.

Desde a segunda metade dos anos 2000, uma nova escola de pensamento, o Novo Desenvolvimentismo, vem propondo uma explicação para o fracasso do modelo nacional-dependente. Para que ocorra o desenvolvimento econômico e o país realize o catching up não bastam educação, investimento na infraestrutura, boas instituições e política industrial. É necessário, adicionalmente, que o país tenha um projeto de desenvolvimento econômico ou de competição internacional, e, segundo, que o governo pratique uma política macroeconômica ativa que garanta que os cinco preços macroeconômicos se mantenham certos, algo que o mercado é incapaz de realizar. É preciso, principalmente, que a taxa de juros se mantenha baixa para que a taxa de câmbio possa ser competitiva e a taxa de lucro esperada seja suficientemente alta para motivar as empresas a investir. Essa política implica que a conta fiscal do país apresente, mais do que um superávit primário, uma poupança pública que financie o investimento público nos setores não-competitivos da economia, principalmente a infraestrutura. Implica, também, que a conta corrente equilibrada ou, se o país tiver o problema da doença holandesa, seja superavitária para que a as entradas de capitais em excesso às saídas não causem a apreciação no longo prazo da moeda nacional e a perda de 
competitividade das empresas industriais competentes. A própria existência de bancos centrais constitui uma admissão da incapacidade do mercado de manter os preços macroeconômicos certos.

Os dois novos fatos históricos que melhor explicam o declínio nas taxas de crescimento, principalmente no Brasil e no México, são a grande crise da dívida externa dos anos 1980 e a submissão ao Consenso de Washington. Esses dois fatores fizeram com que a estratégia desenvolvimentista fosse abandonada até o final daquela década. O Estado liberal adotou com entusiasmo as políticas neoliberais, elevou as taxas de juro para "aprofundar o capital", deixou de neutralizar a doença holandesa e passou a experimentar baixas taxas de crescimento, exceto durante períodos de alta no preço das commodities, como durante alguns anos tempo anos 2000. O Chile foi a exceção a esse respeito, mas vale ressaltar que o país modificou sua política econômica após a crise resultante da experiência neoliberal de 1981 e 1982. A partir de então se tornou menos liberal e manteve um imposto alto sobre a exportação de cobre, neutralizando parcialmente a doença holandesa ${ }^{16}$.

Os países do Leste da Ásia, além de adotarem políticas econômicas independentes, limitando a influência das ideias neoliberais, de terem dado um papel maior à educação, de haverem realizado reformas agrárias importantes no início do sua industrialização e de terem contados com burocracias públicas mais autônomas, contaram com uma grande vantagem em relação aos países latinoamericanos: eles não enfrentam o problema da doença holandesa, que é uma das duas causas de taxas de câmbio apreciadas no longo prazo que desconectam as empresas do país de sua demanda interna ou externa (a outra causa são taxas de juros elevadas para atrair capitais). A doença holandesa só começou a ser conhecida a partir do artigo de Corden e Neary (1982), e as formas de neutralizálas só ficaram claras depois do artigo de Bresser-Pereira (2008). Os países latinoamericanos só lograram se industrializar porque, no quadro do Estado desenvolvimentista, neutralizaram a doença holandesa intuitivamente com o uso de taxas múltiplas de juros ou então tarifas elevadas de importação e subsídios à

\footnotetext{
${ }^{16} \mathrm{O}$ imposto de exportação do cobre neutralizaria completamente a doença holandesa do Chile se sua taxa dependesse da gravidade da doença (ou seja, a supervalorização da taxa de câmbio, que por sua vez varia de acordo com os preços internacionais da produtos básicos).
} 
exportação de manufaturados. Com a submissão ao neoliberalismo essas políticas foram abandonadas e os países passaram a se desindustrializar prematuramente. ${ }^{17}$

\subsection{Modelo social-democrático (segundo desenvolvimentismo)}

Portanto, existem quatro modelos de Estado desenvolvimentista no momento em que os países realizam sua revolução industrial: o central original, o central tardio, o periférico independente e o periférico nacional-dependente. E o que acontece depois da revolução industrial? Nesse estágio, a economia do país é liberalizada. Grã-Bretanha e França seguiram uma política liberal entre as décadas de 1840 e 1920, embora no caso desses dois países não fosse um liberalismo econômico radical ${ }^{18}$. No entanto, nos 30 anos da Era de Ouro do capitalismo após a Segunda Guerra Mundial, foi dominante o quinto modelo de um Estado desenvolvimentista: o Estado desenvolvimentista do bem-estar social. Foi um Estado fruto de um grande pacto desenvolvimentista, porque envolveu uma intervenção moderada mas efetiva do Estado na economia, e social-democrático que buscou atender às demandas das classes populares. Philippe Schmitter (1974) escreveu um artigo paradigmático sobre o corporativismo dos países ricos da Europa que nos quais o pacto corporativista e social-democrático são praticamente a mesma coisa ${ }^{19}$. Adam Przeworski (1985) escreveu um estudo notável sobre a social-democracia no qual deixa claro que ela resultou de uma coalizão de classes ampla envolvendo empresários, trabalhadores e a burocracia pública.

No entanto, nos anos 1970 uma crise econômica, modesta quando comparada com a Grande Depressão dos anos 1930, foi suficiente para que o neoliberalismo - um liberalismo econômico radical e um liberalismo político individualista e conservador apoiado na Escola Neoclássica e a Escola Austríaca voltasse a ser dominante. É uma ideologia reacionária que prega a radical exclusão do Estado da coordenação econômica através de reformas voltadas para o mercado. Embora geralmente conte com o apoio de intelectuais e políticos conservadores, o

\footnotetext{
${ }^{17}$ Em uma conferência organizada em 1989 pelo Instituto de Economias em Desenvolvimento de Tóquio, os países latino-americanos ricos em recursos naturais foram comparados aos países do leste asiático pobres em recursos naturais, mas nenhum dos economistas usou o modelo da doença holandesa para explicar por que os países do leste da Ásia continuaram a crescer rapidamente, enquanto a América Latina ficou para trás desde 1980. O livro da conferência foi editado por Fukuchi e Kagami (1990).

${ }^{18} \mathrm{O}$ Reino Unido apenas abriu sua economia em 1846.

${ }^{19}$ A partir deste paper surgiu uma literatura sobre o Estado corporativista. Ver Schmitter (2017) e Alan Cawson (1985).
} 
radicalismo de suas reformas as torna incompatíveis com o conservadorismo que tem como valores maiores a ordem social e as normas e valores tradicionais. $\mathrm{O}$ novo Estado neoliberal, que foi dominante entre aproximadamente 1980 e a grande crise financeira de 2008, foi uma tentativa fracassada de voltar a um Estado liberal que teria existido no século XIX. Fracassada, primeiro, porque não fazia sentido retornar a um modelo de Estado inferior. Segundo, porque o capitalismo passou por transformações extraordinárias e se tornou muito mais complexo, tornando necessária mais coordenação estatal, não menos. Uma proposta fracassada, em terceiro lugar, porque a globalização, que foi não apenas o resultado de mudanças tecnológicas (principalmente a diminuição no custo dos transportes e das comunicações), mas também de reformas neoliberais patrocinadas pelos Estados Unidos e os demais países ricos, teve como vitoriosos não esses países, mas a China.

\section{Depois do fracasso do Estado liberal}

Desde a crise financeira global de 2008 estamos assistindo ao colapso do neoliberalismo, enquanto o Estado volta a assumir papéis na coordenação econômica. Continua uma ordem social dominantemente conservadora, mas não mais neoliberal. Não houve o retorno a um Estado social e desenvolvimentista como o que existia após a Segunda Guerra Mundial. Os países ricos estão atualmente em meio a uma crise de transição, mas as condições para o retorno ao Estado do bem-estar social e desenvolvimentista não são ainda atendidas. A concorrência dos países em desenvolvimento, que não para de aumentar desde os anos 1970, é uma das explicações para a política neoliberal de redução dos salários. A migração para os países ricos facilita essa redução e leva os trabalhadores brancos dos países ricos a rejeitar os partidos social-democráticos, cujos valores humanitários conflitam com os fechamentos de suas fronteiras para os imigrantes pobres da periferia do capitalismo ${ }^{20}$.

Uma vez que o país se torna capitalista, o mercado assume um papel maior de coordenação, mas isso não significa que o Estado pode e deve deixar de ser

\footnotetext{
${ }^{20}$ Com relação aos custos para os Estados Unidos resultantes do comércio com a China, Autor, Dorn e Hanson (2016, p. 1), concluem que, além dos altos custos regionais envolvidos no fechamento de negócios, o nível nacional de emprego caiu nas indústrias americanas que estão mais expostas à concorrência de produtos importados, como esperado, mas os ganhos de emprego em outras indústrias ainda não se concretizaram.
} 
desenvolvimentista; significa apenas que sua intervenção na economia poderá ser mais moderada do que aquela necessária quando o país realiza sua revolução capitalista. Foi o que vimos na Era de Ouro do capitalismo. Ela constituiu um segundo estágio do desenvolvimentismo para os países centrais originais, no qual a coordenação econômica pelo mercado foi menor do que enquanto estavam se industrializando. Uma das explicações para isto é a crescente diversidade econômica e complexidade tecnológica do desenvolvimento capitalista. À medida que as atividades econômicas adquirem maior diversificação em relação ao nível de diversidade exigido pelas empresas de infraestrutura e das indústrias de insumos básicos do setor não competitivo, o mercado se torna mais eficiente que o Estado na coordenação de numerosas e diversificadas empresas que então surgem. Enquanto a coordenação pelo Estado dos setores não-competitivos da economia é a única possível, já que nesses setores não há mercado ou competição, o mercado é uma instituição mais apropriada quando se trata de coordenar atividades diversificadas que envolvem criatividade e inovação.

Não há, portanto, possibilidade de que o Estado desenvolvimentista desapareça, como os economistas liberais gostariam. Mas significa que o papel econômico do Estado muda. O papel essencial do Estado no campo econômico é criar as condições gerais que permitam às empresas competentes do país competir e estar dispostas a investir. Para isso, o Estado deve manter os cinco preços macroeconômicos (taxa de lucro, taxa de juros, taxa de câmbio, salário e taxa de inflação) em níveis adequados: Isso é algo que o mercado não logra fazer, como podemos ver pelas recorrentes instabilidades financeiras e de preços que caracterizam mercados desregulados. Além disso, deve planejar e investir parcialmente em infraestrutura e indústria básica, adotar uma política industrial estratégica, promover o desenvolvimento científico e tecnológico, promover a redução da desigualdade econômica, defender o meio ambiente, que é um bem público e, é claro, garantir direitos e contratos de propriedade. Portanto, uma vez concluída a revolução industrial, o Estado se retira dos setores competitivos, privatizando-os, enquanto continua a coordenar e, preferivelmente, manter o controle das empresas dos setores monopolistas ou não-competitivos. ${ }^{21}$

\footnotetext{
${ }^{21}$ A industrialização do Japão no final do século XIX foi quase inteiramente realizada pelo Estado. No entanto, por volta de 1910, ocorreu um processo de privatização rápido e radical. No caso da Rússia e da China, suas revoluções, supostamente socialistas, foram, no final das contas, revoluções nacionais e industriais; assim, paradoxalmente, elas fizeram parte da revolução capitalista desses países.
} 
Mas a rejeição ao Estado desenvolvimentista e social continua forte nos países ricos principalmente entre os capitalistas rentistas e os financistas. As pessoas que vivem de rendas capitalistas (juros, aluguéis e dividendos) e os financistas que administram a riqueza dos rentistas ou "investidores" mostram uma clara preferência pelo liberalismo econômico. Entre as causas dessa preferência está o fato de que, nos países em desenvolvimento nos quais o regime de política econômica é liberal e os economistas acreditam ser possível crescer com "poupança externa", ou seja, com déficits em conta-corrente e financiamento externo, a taxa de juros real tende a se manter em nível elevado (mais do que aquele que o risco país justifica). Ora, uma taxa de juros alta é incompatível com uma taxa de câmbio competitiva.

Um problema enfrentado pelos países em desenvolvimento é o grau de conhecimento econômico de suas autoridades. Os Estados desenvolvimentistas que alcançaram bons resultados foram geralmente governados por políticos nacionalistas dotados de espírito republicano, e por economistas pragmáticos e competentes que sabem que sua tarefa fundamental é o desenvolvimento econômico com estabilidade. Os políticos muitas vezes não resistem à tentação de aumentar artificialmente o poder aquisitivo das pessoas sem o aumento necessário da produtividade, praticando o populismo econômico, seja ele o fiscal (o Estado gastando irresponsavelmente mais do que arrecada) ou o cambial (o Estado gastando mais que arrecada, incorrendo em déficit em conta corrente e apreciação cambial no longo prazo. Nos dois casos, o resultado é a apreciação cambial enquanto durar o déficit, a perda de competitividade das empresas e um nível mais alto de consumo e de endividamento externo. Os Estados liberais podem eventualmente evitar o populismo fiscal, mas incidem regularmente no populismo cambial porque acreditam que déficit em conta corrente implica poupança externa que se soma à interna, quando, na prática, antes a substitui do que se acrescenta a ela. Os economistas liberais não sabem e não estão interessados em saber que nos países em desenvolvimento, nos quais a propensão marginal a consumir é elevada, existe uma alta taxa de substituição da poupança interna pela externa. Não sabem, adicionalmente, que qualquer país pode sofrer da doença holandesa, e que este fato mais taxas de juros elevadas durante longo tempo (este um problema apenas dos países em desenvolvimento quando liberam seu sistema financeiro) mantêm a taxa de câmbio apreciada ciclicamente e durante vários anos e, assim, torna não- 
competitivas as melhores empresas industriais do país. Já nos Estados desenvolvimentistas, ainda que até há pouco não houvesse uma teoria legitimando a política cambial, é comum a adoção de políticas de administração da taxa de câmbio de caráter pragmático, porque seus economistas sabem, ainda que de forma intuitiva, quão importante é a taxa de câmbio efetiva para a industrialização. ${ }^{22}$

\section{Conclusão}

Concluindo, o desenvolvimento econômico é o processo histórico de acumulação de capital com incorporação de progresso técnico que aumenta a produtividade e os salários; é um processo de sofisticação produtiva que deriva do emprego de mão de obra cada vez mais qualificada ou sofisticada em atividades com maior valor agregado per capita; é o resultado histórico de uma coalizão de classes desenvolvimentista que reúne políticos e a alta burocracia pública e os trabalhadores com os empresários que respondem pelo investimento e a inovação. Nesse contexto, o Estado desenvolvimentista tem sido e deve continuar sendo uma instituição central do desenvolvimento capitalista, uma vez que é o Estado que garante e regula outra instituição igualmente fundamental: o mercado, uma instituição eficiente em coordenar atividades econômicas competitivas. O Estado tem um escopo de ação muito maior: é o instrumento por excelência para o país alcançar os principais objetivos políticos das sociedades modernas - dois de caráter procedimental (a autonomia nacional e a democracia) e cinco, de caráter final: a segurança, o bem-estar econômico, a liberdade individual, a justiça social e a proteção da natureza - objetivos que devem ser objeto de compromissos e que obedeçam ao princípio da razoabilidade da sociedade. $\mathrm{O}$ desenvolvimento econômico é necessariamente o resultado de uma estratégia nacional de desenvolvimento que surge quando uma nação forte mostra a capacidade de construir um Estado desenvolvimentista e social-democrático igualmente forte ou capaz. As nações apenas permanecem vivas e fortes quando são o produto de um acordo nacional constantemente renovado. Se o contrato social que os une não é forte o suficiente e se as classes sociais que o formam não mantiverem entre si laços básicos de solidariedade, não poderemos falar em estado-nação

\footnotetext{
${ }^{22} \mathrm{~A}$ taxa de câmbio real efetiva é aquela que, através do tempo, se expressa em termos reais, descontada a inflação, e que leva em conta uma cesta das moedas dos países com os quais o país tem as maiores relações comerciais.
} 
desenvolvimentista. O país ficará vulnerável ao pensamento hegemônico dos países ricos, principais competidores dos países em desenvolvimento, e a nação perderá vitalidade, como aconteceu com os países latino-americanos após a grande crise dos anos 1980.

O Estado desenvolvimentista, que se situa entre o Estado liberal e o estatismo, é uma forma superior de organização política e econômica capitalista. É um meio pelo qual a coordenação do Estado e do mercado nas economias capitalistas pode ser combinada de forma sensível ou pragmática. Ao longo da história, houve vários modelos de Estado de desenvolvimento, que dependiam de seu desenvolvimento ser original ou tardio, central ou periférico, primeira ou segunda onda. Todas as revoluções industriais ocorreram dentro da estrutura dos Estados desenvolvimentistas, quando um grupo de políticos nacionalistas conseguiu formar um estado-nação que se industrializou. Essa fase é sempre dominada pelo Estado, que consegue regular um mercado amplo e vasto, no qual as atividades do setor competitivo da economia - que agora são mais diversas e envolvem maior grau de criatividade e inovação - podem ser coordenadas com vantagem pelo mercado. Mas o Estado deve continuar sendo desenvolvimentista, e esse é frequentemente o caso, porque é responsável por coordenar a infraestrutura não competitiva e o setor industrial básico, implementando uma política macroeconômica ativa (que inclui uma política de taxa de câmbio), reduzir a desigualdade econômica e proteger o meio ambiente. É um conjunto de atividades que o mercado não pode realizar.

\section{Referências}

AKAMATSU, K. A historical pattern of economic growth in developing countries. The Developing Economies, Hoboken, Wiley, v. 1, n. 1, 1992.

AMSDEN, A. Asia's Next Giant: South Korea and Late Industrialization. Nova York: Oxford University Press, 1989.

Autor, D.; D. Dorn; G. Hanson. The China shock: learning from labour market adjustment to large changes in trade. Annual Review of Economics, v. 8, n. 1, 2016.

BAIROCH, P. Economics and World History: Myths and Paradoxes. Chicago: Chicago University Press, 1993. 
BARBOSA LIMA, A. Japão: O Capital se Faz em Casa. Rio de Janeiro: Paz e Terra, 1973.

BRESSER-PEREIRA, L. C. The Dutch disease and its neutralization: a Ricardian approach", Brazilian Journal of Political Economy, v. 28, n. 1, 2008.

BRESSER-PEREIRA, L. C. Why did trade liberalization work for East Asia but fail in Latin America? Challenge, v. 62, n. 4, p. 273-277, 2019.

BRESSER-PEREIRA, L. C. Do Desenvolvimentismo Clássico e da Macroeconomia Pós-Keynesiana para o Novo Desenvolvimentismo. Brazilian Journal of Political Economy, v. 39, n. 2, p. 211-235, 2019.

BRESSER-PEREIRA, L. C.; IANONI, M. Developmental class coalitions: historical experiences and prospects. In: MAGARA, H; AMABLE, B. (Orgs.). Growth, Crisis and Democracy: The Political Economy of Social Coalitions and Policy Regime Change. Londres: Routledge, 2017.

BRESSER-PEREIRA, L. C.; OREIRO, J. L. C; MARCONI, N. Developmental Macroeconomics: New Developmentalism as a Growth Strategy. Londres: Routledge, 2014.

CANITROT, A. La experiencia populista de redistribución de ingresos. Desarrollo Económico, v. 15, n. 59, p. 331-351, 1975.

CAWSON, A. Varieties of Corporatism: The Importance of the Meso-level of Interest Intermediation. In: CAWSON, A. (Ed). Organized Interests and the State. London: Sage Publications, 1985.

CHANG, H. Kicking Away the Ladder. Londres: Anthem Press, 2002a.

CHANG, H. The East Asian model of economic policy. In: HUBER, E. (Org.). Models of Capitalism: Lessons for Latin America. Pennsylvania: Pennsylvania State University Press, $2002 \mathrm{~b}$.

CORDEN, W.; NEARY, J. Booming sector and de-industrialization in a small open economy. The Economic Journal, v. 92, n. 368, p. 825-848, 1982.

DÍAZ-ALEJANDRO, C. Southern Cone stabilization plans. In: CLINE, W.; WEINTRAUB, S. (Orgs.). Economic Stabilization in Developing Countries Washington, D.C.: The Brookings Institution, 1981.

EICHENGREEN, B.; PARK, D.; SHIN, K. Growth slowdowns redux. Japan and the World Economy, vol. 32, 2014. 
EVANS, P. Embedded Autonomy: States and Industrial Transformation. Princeton: Princeton University Press, 1995.

EVANS, P. The State as problem and solution: predation, embedded autonomy, and structural change". In: HAGGARD, S.; KAUFMAN, R. (Orgs.). The Politics of Economic Adjustment: International Constraints, Distributive Conflicts and the State. Princeton: Princeton University Press, 1992.

FONSECA, P. Desenvolvimentismo: a construção do conceito. In: CALIXTRE, A; BIANCARELli, A.; CINTRA, M. (Orgs.). Presente e Futuro do Desenvolvimento Brasileiro. Brasília: IPEA, 2014.

FUKUCHI, T.; KAGAMI, M. (Orgs.). Perspectives on the Pacific Basin Economy: A Comparison of Asia and Latin América. Tokio: Instituto das Economias em Desenvolvimento, 1990.

GELLNER, E. The coming of nationalism and its interpretation: the myths of nation and class. In: BALAKRISHNAN, G. (Org.). Mapping the Nation. Londres: Verso, 1996.

GELLNER, E. Nations and Nationalism. Ithaca: Cornell University Press, 1983.

GERSCHENKRON, A. Economic Backwardness in Historical Perspective: A Book of Essays. Nova York: Praeger, 1962.

HAMILTON, A. Report on Manufactures, 1791. Disponível em: $<$ http://bit.ly/1FaVTTg $>$.

IANONI, M. Teoria do Estado desenvolvimentista: uma revisão da literatura. Sinais Sociais, v. 9, n. 24, p. 81-105, 2014.

JAGUARIBE, H. Desenvolvimento Econômico e Desenvolvimento Político, Rio de Janeiro: Fundo de Cultura, 1962.

JANKOWSKA, A.; NAGENGAST, A.; PEREA, J. The middle-income trap: comparing Asian and Latin American experiences. OECD Development Centre's Policy Insights, n. 96, 2012.

JOHNSON, C. The developmental state: odyssey of a concept. In: WOOCUMINGS, M. (Org.). The Development State. Ithaca: Cornell University Press, 1999. 
JOHNSON, C. MITI and the Japanese Miracle. Stanford: Stanford University Press, 1982.

KHARAS, H.; KOHLI, H. What is the middle-income trap, why do countries fall into it, and how can it be avoided? Global Journal of Emerging Market Economies, v. 3, n. 3, p. 281-289, 2011.

KOHLI, A. Coping with globalization: Asian versus Latin American strategies of development, 1980-2010. Brazilian Journal of Political Economy, v. 32, n. 4, p.531-556, 2012.

KOHLI, A. Where do high growth political economies come from? The Japanese lineage of Korea's 'developmental state'. In: WOO-CUMINGS, M. (Org.). The Development State. Ithaca: Cornell University Press, 1999.

LIST, F. National System of Political Economy. Roseville: Dry Bones Press, 1999.

MADDISON, A. Phases of capitalist development. PSL Quarterly Review, v. 30, n. $121,1977$.

PRZEWORSKI, A. Capitalism and Social Democracy. Cambridge: Cambridge University Press, 1985.

SCHMITTER, P. C. Still a century of corporatism? Review of Politics, v. 36, n. 1, p. $85-131,1974$.

SCHMITTER, P. C. Corporatism and Policy-Making in Contemporary Western Europe. Comparative Political Studies, v. 10, n. 1, 1977.

SCHNEIDER, B. The desarrollista state in Brazil and México. In. WOOCUMINGS, M. (Org.). The Developmental State: Ithaca, Cornell University Press, 1999.

SCHUMPETER, J. History of Economic Analysis. Londres: Allen \& Unwin, 1954.

WADE, R. Governing the Market. Princeton: Princeton University Press, 1990.

WOO-CUMINGS, M. The Developmental State. Ithaca: Cornell University Press, 1999. 